\title{
A psicologia e o fracasso/queixa escolar: uma análise das produções científicas
}

\author{
Psychology and school failure/complaint: an analysis of scientific production \\ Psicología y fracaso escolar / denuncia: un análisis de la producción
}

Recebido: 26/07/2021 | Revisado: 31/07/2021 | Aceito: 03/08/2021 | Publicado: 08/08/2021

Paloma Carvalho Alves

ORCID: https://orcid.org/0000-0002-4179-8472 Escola de Saúde Pública Visconde de Sabóia, Brasil

E-mail: Paloma.ca1@hotmail.com

Tereza Cristina Linhares Costa Melo

ORCID: https://orcid.org/0000-0001-8331-3552 Escola de Saúde Pública Visconde de Sabóia, Brasil E-mail: tcristinafisio11@hotmail.com

Jorge Luís Rodrigues dos Santos

ORCID: https://orcid.org/0000-0003-1349-6984 Escola de Saúde Pública Visconde de Sabóia, Brasil E-mail: nutrijorgeluis@gmail.com

Raimundo Ribeiro Machado

ORCID: https://orcid.org/0000-0001-8478-6300 Faculdade Luciano Feijão, Brasil

E-mail: raimundo.machadoii@gmail.com

Fúlvio Holanda Rocha

ORCID: https://orcid.org/0000-0003-2151-5815 Universidade Federal do Ceará, Brasil E-mail: fulvio@ufc.br

Francisco Herlon Ponte de Vasconcelos

ORCID: https://orcid.org/0000-0002-5631-0038

Escola de Saúde Pública Visconde de Sabóia, Brasil E-mail: herlon.vas@hotmail.com

Auxiliadora Elayne Parente Linhares

ORCID: https://orcid.org/0000-0003-2344-5486

Universidade Estadual Vale do Acaraú, Brasil E-mail: elaynelinhares@hotmail.com

Francisco Valdicélio Ferreira

ORCID: https://orcid.org/0000-0002-6347-2844

Escola de Saúde Pública Visconde de Sabóia, Brasil

E-mail: celionutri@gmail.com

Tamires Alexandre Félix

ORCID: https://orcid.org/0000-0001-9297-7764

Secretaria da Saúde de Sobral, Brasil

E-mail: tamiresafelix@gmail.com

\section{Resumo}

A presente pesquisa investigou nas produções científicas da área quais fatores são atribuídos ao fracasso/queixa escolar, analisar o fazer do psicólogo e identificar possíveis intervenções alternativas ao modelo tradicional de culpabilização. Trata-se de uma revisão bibliográfica com de descritores "fracasso escolar" e "queixa escolar", nas plataformas Scielo e Pepsic, publicados na série temporal entre os anos de 2009 a 2018. Encontramos o total de 20 artigos sendo $75 \%$ publicados nos últimos cinco anos. Buscaram-se nos artigos quais as concepções de fracasso/queixa escolar que os autores assinalavam, e quais fatores atribuíam a produção da queixa escolar, e o papel do psicólogo perante essa demanda e se descreviam algum tipo de intervenção voltada para a área. Em $70 \%$ das pesquisas, os autores entendem o fracasso como um fenômeno multifacetado e que o fracasso escolar em sua maioria é produzido por relações dentro e fora do ambiente escolar. Sobre o fazer da psicologia, em $95 \%$ das pesquisas foram assinaladas as necessidades de ressignificação da queixa escolar no ambiente institucional, uma vez que alunos com dificuldade de aprendizagem ou comportamentos que fogem à regra, são tidos com alguma doença biológica, $60 \%$ das pesquisas não mostravam efetivamente como intervir no fracasso/queixa escolar e $25 \%$ indicaram a necessidade de intervenções alternativas em relação a queixa escolar. Com essa pesquisa, destacamos há produções recentes na área da psicologia escolar/educacional e que isso demonstra necessita de maior aprofundamento e estudos científicos que descrevam e discutam a prática concreta do psicólogo.

Palavras-chave: Psicologia escolar; Fracasso escolar; Rendimento escolar; Atuação do psicólogo. 


\begin{abstract}
This research investigated in the scientific productions in the area which factors are attributed to school failure/complaints, analyze the psychologist's actions and identify possible alternative interventions to the traditional model of blaming. This is a literature review with descriptors "school failure" and "school complaint" on the Scielo and Pepsic platforms, published in the time series between 2009 and 2018 . We found a total of 20 articles, $75 \%$ of which were published in the last five years. The authors searched for the conceptions of school failure/complaints that the authors pointed out, and which factors attributed to the production of school complaints, and the role of the psychologist in this demand, and if any type of intervention aimed at the area was described. In $70 \%$ of the researches, the authors understand failure as a multifaceted phenomenon and that school failure is mostly produced by relationships inside and outside the school environment. Regarding the practice of psychology, 95\% of the research highlighted the need for re-signification of the school complaint in the institutional environment, since students with learning difficulties or behaviors that are outside the norm are considered to have a biological disease, $60 \%$ of the researches they did not effectively show how to intervene in school failure/complaints and $25 \%$ indicated the need for alternative interventions in relation to school complaints. With this research, we highlight there are recent productions in the area of school/educational psychology and that this demonstrates that it needs further deepening and scientific studies that describe and discuss the concrete practice of the psychologist.
\end{abstract}

Keywords: School psychology; Academic failure; Academic achievement; Psychologist performance.

\title{
Resumen
}

Esta investigación indagó en las producciones científicas del área qué factores se atribuyen al fracaso escolar / quejas, analizar las acciones del psicólogo e identificar posibles intervenciones alternativas al modelo tradicional de culpar. Trata-se de uma revisão bibliográfica com de descritores "fracasso escolar" e "queixa escolar", nas plataformas Scielo e Pepsic, publicados na série temporal entre os anos de 2009 a 2018 . Encontramos o total de 20 artículos siendo $75 \%$ publicados nos últimos cinco años. En los artículos, los autores buscaron las concepciones de fracaso escolar / quejas, y qué factores atribuían a la producción de las quejas escolares, y el papel del psicólogo en relación a esta demanda, y si se realizó algún tipo de intervención dirigida al área. En el 70\% de las investigaciones, los autores entienden el fracaso como un fenómeno multifacético y que el fracaso escolar se produce mayoritariamente por las relaciones dentro y fuera del entorno escolar. En cuanto a la práctica de la psicología, el $95 \%$ de la investigación destacó la necesidad de resignificación de la queja escolar en el ámbito institucional, ya que se considera que los estudiantes con dificultades de aprendizaje o conductas fuera de la norma tienen una enfermedad biológica, 60\% de los casos. las investigaciones no mostraron efectivamente cómo intervenir en el fracaso escolar / quejas y el $25 \%$ indicó la necesidad de intervenciones alternativas en relación a las quejas escolares. Con esta investigación, destacamos que existen producciones recientes en el área de la psicología escolar / educativa y que esto demuestra que se necesita una mayor profundización y estudios científicos que describan y discutan la práctica concreta del psicólogo.

Palabras clave: Psicología escolar; Fracaso escolar; Rendimiento escolar; Actuación del psicólogo.

\section{Introdução}

A psicologia escolar/educacional foi o primeiro campo da psicologia a surgir no Brasil, sendo o mesmo precedente para a consolidação da profissão no país. Dentre as diversas funções do psicólogo escolar, uma delas é atuar junto aos problemas de aprendizagem que envolvem toda a dinâmica escolar, abordando quais as possíveis causas quelevam ao fracasso escolar e também promovendo intervenções que atuem junto a essas dificuldades (Cassins, 2007). Os problemas de aprendizagem, em geral, são aqueles que envolvem questões de comportamento e de rendimento escolar, de modo que o processo de ensino não se realiza ou ocorre de forma deficitária, gerando o que se denominou de fracasso ou queixa escolar.

Esses “problemas de aprendizagem” que muitas vezes são trazidos pelos pais e professores, geralmente são associados a estigmas que a própria escola atribui aos alunos. Assim, voltam a culpa do desnível em relação aos outros estudantes da mesma série à própria criança que demonstra desinteresse, algumas vezes até patologizando-a por meio de laudos que afirmam que a criança tem algum distúrbio mental e por isso não conseguem acompanhar o restante da turma. (Patto, 1999).

Essa rotulação dada ao aluno resulta na culpabilização da família e/ou da criança por algum distúrbio mental. É importante enfatizar que essa culpa é atribuída ao aluno vindo de um contexto de vulnerabilidade econômica e social, no qual a família não participa do ambiente escolar. No entanto, não é posto que os próprios professores e a escola como um todo, constroem uma imagem da família de classe baixa: pobres, de origem nordestina, com sotaque, muitos filhos, pai ausente. 
críticas e desvalorização do trabalho. (Pereira, 2004).

Patto (1999) sinaliza que alguns dos fatores do fracasso escolar se dão em processos de estigmatização e preconceito nos quais o aluno é visto como aquele que não aprende porque é preguiçoso, fraco, tímido, desinteressado, falta muito às aulas, tem pais separados, a mãe é desleixada, tudo isso sem considerar que a dinâmica escolar ocupa um papel central também no desenvolvimento da aprendizagem da criança. Além disso, a autora afirma que as professoras colocam somente no aluno e em suas condições de vida o desinteresse pelo estudo, sem considerar que a mecanização de tarefas, cópias, punições e ataques à autoestima do aluno poderiam também contribuir para o baixo desempenho escolar.

Para Souza (2006), a queixa escolar não deve estar apenas focada no "aluno- problema", podendo advir de alguma falha do processo de ensino. Assim são necessárias novas relações de ensino, nas quais se insiram novas dinâmicas escolares que procurem não centralizar a queixa nos alunos.

Segundo Souza (1996), os laudos dados pelos psicólogos escolares contribuem diretamente para a estigmatização desses alunos vistos como portadores de algum tipo de queixa escolar, patologizando-os. No momento em que afirmam que a criança tem em um psicodiagnóstico descontextualizado da realidade em que se encontram, os psicólogos reforçam ainda mais a classificação que coloca a queixa escolar como um problema individualizado no próprio aluno, sob o nome de uma psicopatologia, desconsiderando o papel da escola na construção desses problemas.

Para Machado, Fernandes e Rocha (2007), os diagnósticos individualizantes, descontextualizados, estão naturalizados e culpabilizam as vítimas de um processo de escolarização que já está fadado ao fracasso. Os autores dizem ainda que essa naturalização está intrincada pelos modos de vida, de sentir ver e ouvir das pessoas, ou seja, não é tarefa fácil refazer pensamentos nos quais foram tidos como via de regra nas instituições educacionais.

Para que se inicie uma nova maneira de construção dos saberes escolares éimportante que se compreenda como a queixa escolar se instituiu como um processo reduzido a culpabilização somente da própria vítima. Os problemas de escolarização perpassam a grande maioria das salas de aula. Ao adentrar em uma escola, surgem diversos problemas comuns em todas elas, sendo que um dos mais frequentes são as dificuldades de aprendizado e de mau comportamento, um entrelaçado ao outro, ou mesmo separados. O discurso escolar geralmente está pautado em responsabilizar o aluno por não atender as expectativas de rendimento que a escola, família e professores esperam da criança. Isso porque se entende que o estudante não aprende ou porque não se comporta como esperado ou porque tem alguma dificuldade individual de aprendizagem, ou mesmo as duas coisas, sem na maioria das vezes ter o questionamento de qual o papel da escola no processo de ensino do aluno.

Como afirma Patto (1999), essa atribuição individualizante dos problemas de aprendizagem nas crianças estarem pautados na sua dinâmica familiar, é reforçado pela Teoriada Carência Cultural. Essa teoria, segundo a autora, diz que devido às crianças pobres viverem em um ambiente carente, hostil e desprovido de cultura, não teriam condições de aprender, pois não teriam como ter acesso aos estímulos culturais no ambiente em que vivem.

Essa teoria distingue do ambiente de crianças ricas, que por serem de classes mais abastadas possuiriam uma "família estruturada" e assim poderiam se desenvolver plenamente na escola. A teoria claramente isenta o papel da escola no processo de ensino-aprendizagem, ao não refletir como a instituição escolar desconsidera outras culturas e acaba por supor um déficit dedesenvolvimento no aluno de culturas diferentes, dando lugar mais uma vez a particularizaçãodo fracasso escolar nas próprias vítimas.

Com essa patologização da queixa escolar, as demandas para os serviços depsicologia das universidades têm crescido consideravelmente, com encaminhamentos principalmente advindos das escolas. Souza (1996) traz diversas pesquisas que apontam que a grande maioria dos encaminhamentos para serviços de psicologia na faixa de idade de seis aoscatorze anos tem como origem a queixa escolar. Um dado importante que a autora assinala é que a maioria desses encaminhamentos é para 
meninos, com sua maior parte entre sete e nove anos, tendo como principal queixa problemas de escolarização e comportamento.

Esses dados mostram que é prática comum na escola fazer encaminhamentos médicos e psicológicos para crianças com os chamados "problemas de escolarização". Também indicam que boa parte dos atendimentos infanto-juvenis nas clínicas de psicologia trazem como demanda a queixa escolar. Aqui cabe ressaltar que essas conduções medicalizantes dadas a esses casos claramente estão relacionadas no que diz respeito aconstante patologização e centralização das queixas escolares.

Souza (1996) relata ter encontrado nos serviços de psicologia um atendimento à queixa escolar puramente clínico, com hipóteses ligadas a problemas familiares e específicos do indivíduo. Até mesmo quando eram serviços de psicologia escolar, a autora relata que a prática, mesmo que em ambiente escolar, trabalhada com pais e professores, é muito próxima da prática clínica, pois coloca como centro de mudança uma suposta interioridade da criança com queixa escolar.

Para Machado e Souza (2004), esse discurso de responsabilização somente da criança como produtora de sua queixa legitima distorções sobre as reais causas do baixo desempenho e colabora para a perpetuação patologizante da queixa escolar. Patto (1999) afirma que é preciso ver o fracasso escolar como um fenômeno complexo e multifacetado, de maneira que a centralização, só no aluno ou na família, individualiza ainda mais a situaçãodos alunos que apresentam dificuldades. Assim sendo necessário que todas as relações escolares sejam amplamente discutidas a fim de integrar junto com a família e todos aqueles que fazem parte da comunidade escolar, a constante construção, aplicação e avaliação do processo de educação escolar.

Entendendo que existem diversos fatores que conduzem à produção do fracasso escolar, é importante que investigue como a literatura disponível nos últimos anos tem compreendido esse fenômeno e indicado possíveis intervenções na queixa escolar. De modo que a presente pesquisa pretendeu compreender como são concebidas as queixas escolares e o fazer do psicólogo diante delas nas produções acadêmicas da área. Para isso, o trabalho aqui proposto terá como objetivos específicos, compreender como a queixa escolar é entendidapela literatura nacional em periódicos de psicologia nos últimos dez anos, investigar quais fatores são atribuídos na produção do fracasso escolar, analisar o fazer do psicólogo escolar diante do fracasso escolar e identificar intervenções alternativas ao modelo tradicional de culpabilização.

\section{Metodologia}

Foi realizada uma pesquisa bibliográfica. Para Gil (2002), a pesquisa bibliográfica é aquela que é desenvolvida a partir de material já existente, constituídaprincipalmente de livros e artigos científicos. O mesmo autor aponta como vantagem da pesquisa bibliográfica o fato do investigador poder ter uma cobertura mais ampla do fenômeno investigado.

Então, dessa forma priorizamos a busca em artigos científicos, por eles poderem mostrar uma produção mais recente na área. Sendo assim, foram pesquisados nas plataformas online Scielo e Pepsic artigos que apresentassem como tema principal fracasso/queixa escolar.Como critérios de inclusão, foram selecionados artigos:

1. Publicados no período dos últimos dez anos (2009-2018).

2. Publicados em periódicos de psicologia.

3. Que abordem o fracasso/queixa escolar em contexto escolar ou serviços depsicologia.

4. Que apresentem pesquisas empíricas.

Como critérios de exclusão, os seguintes trabalhos não serão analisados:

1. Ensaios ou resenhas

2. Revisões de literatura 
3. Artigos que não se enquadrem no período delimitado

4. Trabalhos que tragam o fracasso/queixa escolar no ensino superior ou contextos não-escolares (exceto serviços de psicologia).

5. Artigos que não estejam na área de psicologia escolar/educacional.

6. Artigos puramente conceituais.

No total foram encontrados 96 trabalhos nos últimos dez anos. Primeiro, foram pesquisados artigos com o descritor "fracasso escolar" na Plataforma Scielo e depois com o descritor "queixa escolar". Na plataforma PepSic foi feito o mesmo procedimento. Os artigos foram lidos na íntegra e selecionados a partir dos critérios de inclusão e exclusão citados acima. Além disso, os trabalhos foram lidos buscando o conceito de fracasso/queixa escolar considerado, quais os fatores que produzem do fracasso/queixa escolar, qual a prática do psicólogo escolar diante do fracasso/queixa e se algum trabalho assinala alguma intervenção alternativa ao modelo de culpabilização do aluno.

Na plataforma Scielo, foram encontrados 51 artigos ao todo. Com o descritor "fracasso escolar" obtiveram-se 31 artigos, dos quais três abordavam pesquisas em contextos não escolares, sete estavam voltados para a área da pedagogia, um tratava do fracasso escolar no ensino superior, quatro eram revisão de literatura, um estava na área de psicologia do desenvolvimento, dois eram ensaios e quatro eram estudos não empíricos. Nessa pesquisa, foram considerados nove artigos pertinentes com a proposta de análise do presente trabalho. Na mesma plataforma, com o descritor "queixa escolar" foram encontrados 20 trabalhos, sendo seis repetidos, três em contextos não-escolares, três eram resenhas, um estava na áreade psicologia do desenvolvimento e um na área de educação física. Foram considerados seis artigos com esse descritor. No total, nessa plataforma foram considerados para a pesquisa 15 trabalhos.

Na plataforma Pepsic, foram encontrados 45 artigos no total. Com o descritor "fracasso escolar" foram encontradas 39 produções, das quais duas eram revisão de literatura, uma estava em um contexto não-escolar, três estavam na área da psicologia clínica, três se tratavam de artigos puramente teóricos, 23 não estavam no período de anos selecionado, uma era da área de psicologia do desenvolvimento, duas eram da área da pedagogia e duas estavam repetidas. Foram considerados três artigos com esse descritor. Com "queixa escolar" foram encontrados seis artigos, dos quais quatro não estavam no período de anos delimitado e dois artigos eram pertinentes com o presente trabalho. Nesta plataforma foram considerados cinco artigos. $\mathrm{O}$ total selecionado, juntando o quantitativo das duas plataformas, foi de 20 trabalhos (Anexo B), ficando de fora da pesquisa 76 artigos (Anexo A) por não se encaixarem nos critérios de inclusão.

Para a análise dos dados, foi feita uma revisão integrativa de literatura acerca do tema fracasso/queixa escolar, aqui entendidos como sinônimos, por tratarem de temas adjacentes à mesma problemática. Segundo Botelho, Cunha e Macedo (2011), a revisão integrativa de literatura é uma síntese de tópicos para uma construção extensa de um determinado conhecimento. Os autores ainda afirmam que os artigos de revisão são um tipode pesquisa que podem ter como fonte meios eletrônicos ou bibliográficos para obter resultados de pesquisas de outros autores, para que assim seja construído um estado da arte deum determinado tema. Assim, com esse tipo de pesquisa produzem-se novos conhecimentos científicos, pois ao analisar fontes de dados e uma diversidade de trabalhos de autores que produziram ao longo de um período de tempo sobre um tema, é possível se apontar lacunas e apresentar novas proposições sobre o que se está sendo estudado (BOTELHO, CUNHA, MACEDO, 2011). A seguir serão apresentados os resultados e análises feitas a partir da pesquisa realizada.

\section{Resultados e Discussão}

A partir da análise prévia dos artigos, foram selecionados 20 estudos (Anexo B). Tais artigos foram classificados levando em conta o ano de publicação, o conceito de fracasso/queixa escolar considerado, o que pode produzir o 
fracasso/queixa escolar, o fazer do psicólogo escolar e quais as possíveis intervenções apresentadas para com a problemática.

Em relação aos anos de publicação, percebemos que dos estudos selecionados, 75\% (15 trabalhos) foram produzidos nos últimos cinco anos, de 2014 a 2018. É importante dizer que tem ocorrido uma recente produção de trabalhos sobre fracasso/queixa escolar nos últimos anos.

Gráfico 1 - Distribuição dos artigos analisados por ano.

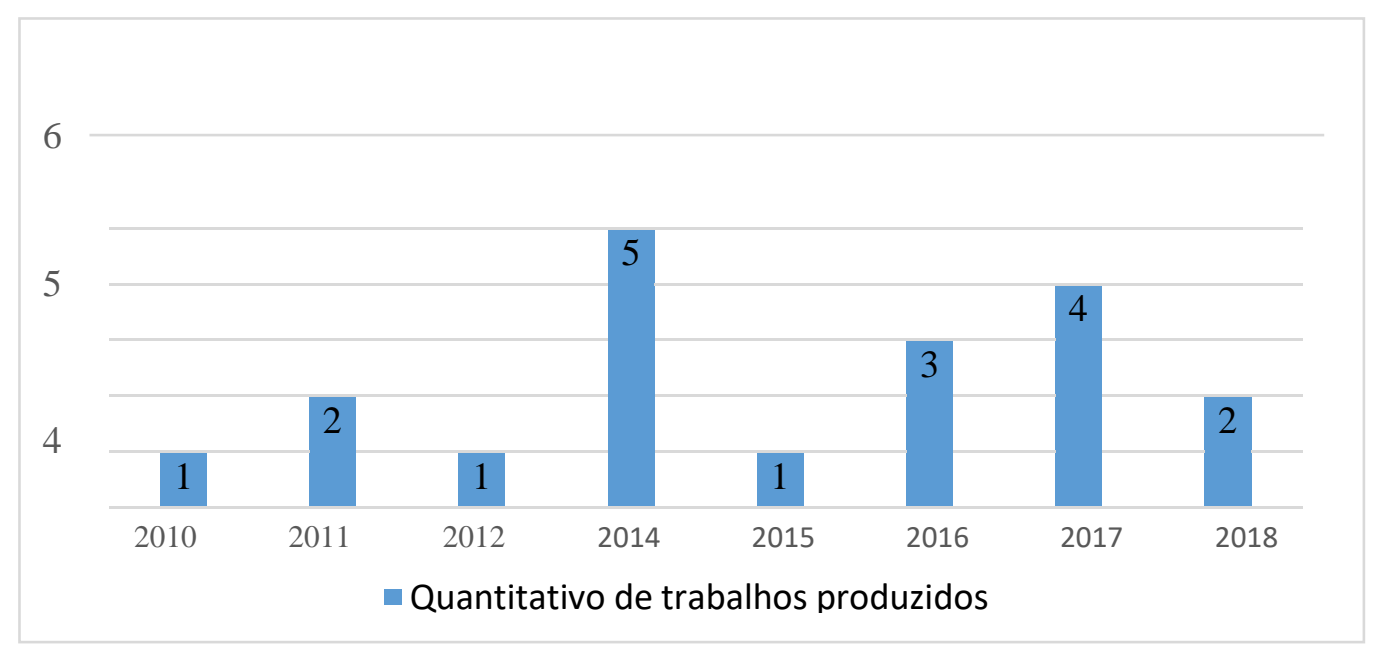

Fonte: Dados da pesquisa.

Com relação à distribuição de ciclos da educação básica nos quais os artigos selecionados se encaixavam, 30\% dos trabalhos foram desenvolvidos no Ensino FundamentalI (seis trabalhos), 15\% no Ensino Fundamental II (três trabalhos), 5\% no Ensino Fundamental I e II (um trabalho), 5\% no Ensino Fundamental I e II e EJA (Educação de Jovens e Adultos), 5\% dos trabalhos apenas especificaram como Ensino Fundamental (um trabalho), 5\% (um trabalho) em uma APAE (Associação de Pais e Amigos dos Excepcionais), 10\% (dois trabalhos) foram desenvolvidos no ciclo de educação EJA (Educação de Jovens e Adultos) e em $25 \%$ dos trabalhos não foram apresentados dados específicos sobre quais ciclos da educação básica foram trabalhados (cinco trabalhos).

Tabela 1 - Distribuição de artigos pelos ciclos da Educação Básica

\begin{tabular}{lc}
\hline Ciclos da Educação Básica & Número de Artigos (\%) \\
\hline Ensino Fundamental I & $30 \%$ \\
\hline Ensino Fundamental II & $15 \%$ \\
Ensino Fundamental I e II & $5 \%$ \\
Ensino Fundamental I e II e EJA & $5 \%$ \\
Ensino Fundamental & $5 \%$ \\
APAE & $5 \%$ \\
EJA & $10 \%$ \\
Não especificados & $25 \%$ \\
Total & $\mathbf{1 0 0 \%}$ \\
\hline
\end{tabular}

Fonte: Dados da pesquisa.

Os dados encontrados sobre as séries em que mais se direcionam os trabalhos sobre queixa escolar (12 trabalhos - 
60\%), deixam claro que nos Ensinos Fundamental I e II há uma maior preocupação com esse tipo de problema por parte da produção em psicologia. Souza e Sobral (2007, p. 129) afirmam que "podemos pensar que este é o período (Ensino Fundamental) em que mais se espera que o psicólogo possa ajudar as crianças a se saírem bem na escola". Pode-se assim pensar que nessa etapa na qual as crianças estão se construindodentro do ambiente escolar, a família e a escola ainda estão buscando estratégias de como veem e como podem intervir no fracasso escolar. Também é importante chamar a atenção que não houve incidência de nenhum trabalho voltado exclusivamente para o Ensino Médio. Isso acaba por levar à reflexão que Souza e Sobral (2007) já haviam chegado em seu trabalhosobre a Orientação à Queixa Escolar: depois de toda uma vida estudantil de fracasso escolar, o adolescente, sua família e a escola já não veem mais opções de como superar o problema, assim nem chegando a procurar atendimento psicológico. Além desse fato, fica o questionamento do porquê a psicologia não está publicando sobre esse ciclo da educação básica que se encontra tão negligenciado nas produções acadêmicas.

Sobre o conceito de fracasso/queixa escolar encontrado nos artigos, em $70 \%$ dos trabalhos (14 artigos) corroboraram com a concepção de que o fracasso escolar é um fenômeno multifacetado, não envolvendo só o aluno ou professor ou família, mas sim toda a dinâmica da rede escolar. Negreiros et al $(2017$, p. 2) falam que "é oportuno enfatizar que o fracasso escolar possui raízes em diversos seguimentos intra e extraescolares, e todos os envolvidos no processo educacional respondem, direta ou indiretamente, pela manifestação detal fenômeno". Ainda para Ramos e Stella (2016, p. 194) o fracasso escolar apresenta uma

[...] tendência à culpabilização do aluno por seu baixo desempenho,responsabilidade esta que no máximo é estendida à família sem se considerar as questões políticas, pedagógicas e sociais. No entanto, salienta-se que se deve mudar o olhar sobre o fenômeno do fracasso escolar e deixar de vê-lo como responsabilidade de um, ou outro, mas observá-lo de maneira multifacetária.

Em 5\% dos trabalhos (um artigo), o fracasso/queixa escolar foi ligado à repetência e constantes reprovações. Para Pezzi e Marin (2016, p. 220) o conceito de fracasso escolar é usado "para se referir à distorção entre idade e ano (Lei n. 9.394,1996; Resolução CNE/CEB n. 4, 2010; Parecer CNE/CEB n. 7, 2010) de dois ou mais anos de ensino (SMED-SL, 2012), que decorre de sucessivas reprovações". Esse conceito de fracasso escolar nos leva a pensar que essa concepção pode ser ainda reducionista, uma vez que não leva em conta os significados que o aluno tem para com a escola, como é sua relação com professores e colegas, quais significados e estigmatizações esses têm para com o aluno que reprova, como éa relação escola-família e como o próprio aluno se vê como sujeito implicado no processo de aprendizagem.

Em 20\% dos trabalhos (quatro artigos) a queixa escolar foi concebida comoproblemas comportamentais. É entendida como um problema de comportamento, no qual geralmente as instituições de ensino encaminham a algum tipo de serviço de saúde, desresponsabilizando-se de qualquer contribuição para a produção da queixa. Oliveira, D’Abreu e Maturano (2011) apud Elias e Maturano (2014, p.36) demonstram a centralização do fracasso escolar quando dizem que

A expressão "queixa escolar" remete à condição particular em que se encontram as crianças encaminhadas para atendimento externo à escola, por não acompanharem sua turma em termos de desempenho, notadamente em leitura e escrita. Com frequência, a queixa escolar está associada a problemas de comportamento externalizantes.

Em um trabalho (5\% dos artigos) o fracasso/queixa escolar foi tido como um problema individualizado no aluno, em sua não motivação para o aprendizado. Para Garcia e Boruchovicht (2014, p. 278) "As atribuições de causalidade são mais compatíveis com a motivação para aprender, quando o sujeito atribui causas internas e controláveis ao desempenho escolar obtido, como o esforço", de forma que nesse trabalho é mostrado claramente que o aluno depende somente de si para ter um 
bom resultado escolar.

Podemos assim dizer que a concepção do fracasso escolar como um fenômeno produzido pelas diversas relações contidas no ambiente escolar é predominante nos artigos produzidos nos últimos dez anos. Entretanto, é possível se destacar que, mesmo com o baixo número de trabalhos que individualizam o fracasso/queixa escolar no aluno, ainda se ter esse tipo de produção dentro do ramo da psicologia pode demonstrar que ainda permanece esse ponto de vista centralizado. Provavelmente, havendo maior investimento na produção científica sobre fracasso escolar, chegue-se a uma visão mais crítica e sistemática sobre como trabalhar esse problema.

Com relação aos fatores que contribuem para a produção do fracasso escolar, em 70\% dos trabalhos (14 artigos) foi predominante a compreensão de que o fracasso/queixa escolar é produzido por uma rede de relações, que vão desde a falta de compreensão da realidade social do aluno à inadequação da escola pública em lidar com esse estudante. Há também um trabalho que fala sobre atribuições que colocam os fenômenos da patologização e medicalização como produtores da queixa escolar, quando na verdade deveriam levar em consideração as relações envolvidas no ambiente escolar.

[...] a escola pode ser um espaço de produção da queixa escolar. Consideramos, ainda, que essa queixa abrange uma noção de produção histórico-social, pois se a escola pertence a uma sociedade marcada por desigualdades sociais e econômicas entre grupos e classes, o fracasso escolar se apresenta, antes de tudo, como um fracasso social (Bray, Leonardo, 2011, p.253).

Em 5\% dos artigos (um trabalho) as causas para a produção do fracasso escolar foram dadas as crenças do professor de que o aluno proveniente de família de baixa renda nãoaprenderia, centralizando assim a produção do fracasso/queixa escolar na visão que o professor tem do aluno. Para Paiva e Del Prette (2009, p. 76)

O que se percebe, portanto, é que dependendo da forma como se configuram, as crenças educacionais dos professores podem representar condições reconhecidamente dificultadoras da aprendizagem dos alunos como, por exemplo, acreditar que o aluno não é capaz de aprender e/ ou ter baixas expectativas quanto aodesempenho escolar do mesmo.

Dois estudos (10\% dos artigos) compreenderam que a não aprendizagem escolar éum problema unicamente advindo do estudante por conta de seu comportamento que foge à regra, os autores afirmando que "programas promotores de competência social favorecem a redução dos problemas de comportamento e o progresso acadêmico" (Elias e Marturano, 2014, p.36).

Em 15\% dos trabalhos (três artigos), foram apresentados dados sobre os dispositivos de saúde e conselhos tutelares como produtores do fracasso/queixa, isso porque essas instituições ao acolherem as demandas, que as escolas diagnosticam e as enviam, de alunos que não aprendem porque têm algum distúrbio, legitimam a desresponsabilização da escola no processo de ensino-aprendizagem e promovem práticas estigmatizadoras e excludentes que contribuem para essa produção. Zibetti, Souza e Queiróz (2010, p. 503) constaram que ao encaminhar as crianças para atendimento psicológico

[...] as escolas eximem-se de responsabilidades, pois o 'problema' saiu do âmbito escolar e está nas mãos dos órgãos competentes, ou seja, o Conselho Tutelar e o sistema de saúde. E estas duas instâncias, acolhem e respondem às demandas escolares, contribuindo para a manutenção de práticas excludentes e estigmatizantes que não têm contribuído para a superação do fracasso escolar.

Diferentes fatores que produzem o fracasso/queixa escolar se apresentaram nos artigos encontrados. Nesse ponto é importante destacar que os estudos estão se voltando para multiplicidade de aspectos que geram esse fenômeno. Mesmo com alguns trabalhos ainda centralizando a queixa em apenas algum fator da escola, seja ele aluno, professor ou família, podemos compreender que o fracasso escolar já tem uma visão mais ampla e variada sobre como a diversidade da dinâmica escolar pode 
influenciar para sua produção.

Sobre o fazer do psicólogo no ambiente escolar em relação ao fracasso/queixa escolar, oito artigos (40\% dos trabalhos) mostram que o trabalho do psicólogo deve servoltado para a ressignificação da queixa escolar, conhecendo as várias engrenagens queformam a escola e discutindo as diversas relações estereotipadas que se têm sobre as criançase suas famílias. Para Paiva e Del Prette (2009, p. 84) conhecer "crenças e identificar padrões presentes no cotidiano da escola representam um esforço inicial" de entender como a queixa escolar pode ser desnaturalizada no interior das instituições, buscando a partir disso apontar o que leva ao fracasso escolar. Para que de fato se tenha uma ressignificação da queixa, Bray e Leonardo (2011, p.253) dizem que "[...] a Psicologia, numa vertente crítica, pode oferecer valiosa contribuição, trazendo à Educação novas compreensões acerca da queixa/fracasso. Essa concepção crítica da Psicologia Escolar nos incita a repensar a prática do psicólogo".

Em 45\% dos artigos (nove trabalhos) é predominante que o psicólogo antes de tudo tem que conhecer o papel de todos os atores envolvidos no processo de escolarização. Pozzobon, Mahendra e Marin (2017, 394) afirmam que o "[...] trabalho de equipe envolvido é indispensável no processo de ensino-aprendizagem, no qual alunos, pais, professores, escolase políticas públicas se tornem mais adequados, trabalhando juntos em sinergia, para que todos obtenham sucesso". Ainda segundo Asbahr, Martins e Mazzolini (2011, p. 167) "é necessário que o psicólogo compreenda como são organizadas as relações escolares, a dinâmica institucional da escola e os preconceitos engendrados no cotidiano escolar". De forma que buscando apreender como todos esses se relacionam, como são construídas suas histórias no ambiente escolar, observando os estereótipos e considerando a dimensão social, poderão ser identificados os mecanismos geradores do não-aprender.

Em dois artigos (10\% dos trabalhos) falou-se sobre a despatologização que a psicologia pode vir a sustentar, de forma a não procurar e nem favorecer falas biologizantes que as crianças com queixa escolar carregam. Para Benedetti et al (2018, p. 79)

“[...] cada vezmais cedo as crianças são submetidas a diagnósticos psicopatologizantes, sendo a partir destesprescritos o uso de psicofármacos, que tentam tratar os sintomas desconsiderando o contexto escolar, familiar, social e histórico no qual a criança está inserida".

Em um artigo (5\% dos trabalhos), propõe-se que o trabalho do psicólogo frente a queixa escolar pode ser o atendimento clínico, como o apresentado no artigo que se desenvolveu com oficinas grupais dentro de um serviço de psicologia (Elias e Marturano, 2014). Esse tipo de produção, pode nos levar a pensar que ainda existe a visão clínica de atendimento à queixa escolar. Apesar de um atendimento diferente do individual ser apresentado no artigo citado, não intervir no interior da escola e da dinâmica escolar e sem conhecer todos os atores que dela participam, demonstra que ainda não se reconhece a rede de relações que produzem o fracasso escolar.

O trabalho do psicólogo apresentado na maioria das produções demonstra que a área já entende que não existe somente um fator ou um responsável pelo fracasso escolar. De maneira que 95\% (19 artigos) dos trabalhos defendem que para se interceder nessa demanda do cotidiano escolar é necessário que se atue sobre as várias relações que levam a esse fenômeno multifacetado. É interessante destacar que, contudo, em 70\% (14 artigos) dostrabalhos se diz que a queixa escolar é produzida também devido a uma multiplicidade de fatores. Assim, é notada a diferença entre os índices, uma vez que a grande maioria dosautores por mais que afirmem que o trabalho do psicólogo deve se voltar em algum momento para a diversidade de relações e atores envolvidos no cotidiano escolar, ainda parece que nem todos reconhecem de fato a complexidade que leva ao fracasso escolar.

No que diz respeito às formas alternativas de intervenção à queixa escolar, dos artigos analisados, apenas cinco (25\%) modelos de intervenção que diziam como trabalhar a questão do fracasso escolar. O trabalho de Oliveira, Bragagnolo e 
Souza (2014), aconteceuem um serviço-escola de psicologia no qual foram trabalhadas alternativas, de como compreender e agir com estudantes com queixa escolar, junto com pais, escola e professores, todos eles tomados como parte fundamental do processo de formação dos alunos. Foram feitas entrevistas, oficinas, trocas de experiências e ressignificação do que se compreender porqueixa escolar, além de procurar conhecer como se constitui a dinâmica escolar e como são as condições de trabalho do corpo docente.

No artigo de Asbahr, Martins e Mazzolini (2011) foi relatado uma experiência de estágio em psicologia escolar, a qual se propunha a ressignificar os modos de como opsicólogo atualmente deve trabalhar o atendimento à queixa escolar. De modo que, para além de supervisões clínicas e atendimento ao cliente, houve contato com pais, professores e escolapara que todo o ambiente e pessoas que formam a escola fossem incluídos nessa proposta.

No artigo de Bulhões (2018), com os pais, a escola e a criança, foi construída uma nova forma de compreender a queixa escolar. Com os pais, foram feitas entrevistas e visitas domiciliares a fim de investigar o histórico escolar da criança. Como proposta de intervenção no segmento família, foram realizadas visitas semanais nas quais as estagiárias de psicologia puderam discutir possibilidades de participação ativa no processo de aprendizagem, assim como fornecer apoio na rotina de estudos da criança. Com as crianças houve observações em sala de aula, as quais serviram como subsídio para o acompanhamento individual que aconteceu posteriormente a fim de compreender como se constitui o processo de aprendizagem daquele aluno. Com as professoras foram feitas entrevistas a fim de saber comosignificavam queixa escolar e como isso se mostrava no ambiente da sala de aula. Para com professores foi-se apresentado princípios da Psicologia Histórico-Cultural, mostrando como funciona o processo de aprendizagem da escrita. Também houve uma parceria entre as estagiárias de psicologia e as professoras para planejamento e execução de ações que trabalhassem de maneira diferenciada com crianças que apresentassem alguma queixa de aprendizado. Além disso, houve a criação de um espaço de reuniões com pais e escola, com o objetivo de informar e diminuir o caráter punitivo que antes existia nessas reuniões, permitindo assim que a partir desses encontros fossem dadas novas ressignificações à queixa escolar.

No trabalho de Lima, Prado e Souza (2014), a proposta foi feita em um serviço- escola de psicologia com adolescentes e seus projetos de vida, investigando como a situação de fracasso escolar foi constituída durante toda sua vida estudantil. Apesar de se tratar de um contexto clínico de intervenção, procurou-se ir à escola e ter reuniões com os professores dos adolescentes a fim de mediar relações com o ambiente escolar para que em parceria com o atendimento psicológico do jovem, acompanhado de seus pais, possa surtir mudanças tambémno contexto escolar.

No trabalho de Bittencourt, Lima e Gesser (2017) foi feita uma parceria entre uma turma de $3^{\circ}$ ano do Ensino Fundamental e estagiárias de um curso de psicologia. A professora da turma já não via como alguns de seus alunos, que estavam atrasados em relação aos demais, poderiam aprender, pois estes não conseguiam seguir regras de comportamento no ambiente de sala de aula. Sendo assim, o objetivo foi trazer um novo significado para a queixaescolar, assim como uma nova percepção sobre as dificuldades e potencialidades das crianças da turma que apresentavam alguma queixa de aprendizado. Houve entrevistas, observações e conversas informais para que se fosse pensado e implantado um plano de ação. Esse plano se constituiu no desenvolvimento do trabalho em grupo, no qual foram desenvolvidas oficinas, apresentação de desenhos e textos coletivos, nos quais as estagiárias iam apresentando como agir em coletividade pode ajudar no desenvolvimento de atividades na sala de aula. Esse exercício proporcionou que houvesse mudanças nas relações de professor-aluno e aluno-alunoe mesmo uma descristalização da visão da professora de que os alunos poderiam aprender e não como um problema de comportamento. Destacou-se também a limitação, de que apesar de considerar a família com um do papeis importantes da dinâmica escolar, não foi possível englobá-la.

Outros 12 trabalhos (60\% dos artigos) falava-se que o atual cenário de percepção da queixa escolar precisa mudar e que devem se construir novas práticas para com o fracasso/queixa escolar, no entanto não diziam como. Apesar de reconhecer 
que a área da psicologia escolar deve elaborar novas formas de atuar frente a essa necessidade, as produções científicas parecem ainda não apresentarem de fato como executar essas ações.

Ainda 3 artigos (15\% dos trabalhos) indicam algum tipo de intervenção à queixa escolar, mas acabaram por particularizar o problema no aluno. A proposta estudada por Pezzie Marin (2016), apresenta as classes de aceleração que de início se mostraram como uma alternativa às reprovações. No entanto, podemos falar que ao se analisar a ideia como um todo, essas classes acabam por centralizar o problema no aluno. Isso porque a queixa escolar não foi trabalhada numa parceria entre a família e a escola, uma vez que o objetivo dessas classes é não haver tantas reprovações e não uma ressignificação da queixa que procurasse entender como esses problemas de reprovação surgem.

No artigo de Elias e Maturano (2014), procurava-se avaliar duas intervenções em queixa escolar. No entanto após analisar o conteúdo do trabalho, podemos dizer que as duas acabaram por individualizar o problema no aluno, pois uma tinha ênfase na superação de problemas do próprio aluno e a outra estava voltada para o contexto clínico, por meio de experiências de aprendizagem mediada. Em nenhuma das duas, falou-se em contato com professores, escola ou família, ou até mesmo sobre uma compreensão crítica acerca dofracasso escolar.

O trabalho de Silva e Rodrigues (2014) reconhece que é necessária uma parceria entre escola, família e estudantes para uma ressignificação dos problemas escolares, todavia expõe um atendimento puramente clínico quando se trata de queixa escolar, sem um contato com a realidade da instituição que as crianças pertencem. Assim, podemos mais uma vez afirmar que apesar de fazer uma análise crítica sobre queixa escolar, a proposta interventiva ainda não foi pensada criticamente.

Por fim, refletimos acerca dos resultados encontrados e analisados nos artigos considerados nesta pesquisa. Primeiramente que se tem uma larga visãocrítica sobre o que é o fracasso escolar (70\% - 14 artigos), com toda a diversidade de fatores que o produzem. Com relação aos fatores que contribuem para a produção da queixa escolar, 70\% dos artigos (14 trabalhos) afirmam que ela é produzida pela rede de relações formadas entre alunos, família e escola, que vão desde a falta de conhecimento sobre a realidade social do aluno e sua família à inadequação dos professores e da escola em lidar com esse estudante. Em 19 trabalhos (95\%) falou-se que o trabalho do psicólogo frente a esse fenômeno deve ser voltado para ressignificação da queixa e do conhecimento sobre toda a rede de relaçães e a dinâmica que ocorrem na instituição escolar. Esses dados podem demonstrar que as atuais produções acadêmicas estão em consonância com a perspectiva crítica do fracasso escolar. Noentanto, quando partimos para a análise das intervenções, apenas $25 \%$ dos artigos (5 trabalhos) mostraram de fato formas alternativas aos modelos individualizantes e estereotipados que geralmente existem nas instituições. Isso nos leva a pensar que a psicologia ainda tem um longo caminho a percorrer sobre como trabalhar a queixa escolar, uma vez que é preciso ir além da criticidade de como esse fenômeno é produzido, para também apresentar modos de fazer do psicólogo diante dessa demanda.

\section{Considerações Finais}

A presente revisão bibliográfica pretendeu compreender como são concebidas as queixas escolares e o fazer do psicólogo diante delas nas produções acadêmicas da área. Os estudos analisados demonstraram como o fracasso/queixa escolar vem sendo entendido e estudado pela psicologia nacionalmente, de maneira que podem ser uma fonte deconhecimento importante tanto para profissionais da psicologia como da educação, além de pesquisadores da área.

Ao se considerar o número de artigos da temática em psicologia conforme nossos critérios de inclusão, podemos enunciar que se tem uma relativa baixa produção em relação aonúmero de anos selecionados, tendo em média apenas dois trabalhos por ano. Ademais, deve- se considerar que 75\% dos artigos (15 trabalhos) selecionados foram publicados nos últimos cinco anos. Assim, parece que o tema deste artigo vem sendo mais relevante nos últimos anos devido ao maior número de concentração de artigos produzidos mais recentemente. 
Um dado importante da pesquisa foi de que nenhum artigo analisado tratou da queixa escolar no ensino médio. Aparentemente as produções em psicologia escolar/educacional ainda não se voltam para esse público adolescente, não contribuindo assim para práticas que acolham também as necessidades de escolarização de alunos que provavelmente chegaram ao ensino médio com toda uma história estudantil de negligência e estigmatização escolar.

Ainda pode-se dizer que ainda são necessárias pesquisas de base empírica sobre como intervir em queixa escolar. Os estudos na área são amplos, a educação e a psicologia entendem que grande parte dos moldes hoje aplicados nessa área precisa mudar e que tambémos conceitos e fatores entendidos precisam ser ressignificados para escolas, pais, professores ealunos. No entanto a psicologia e a educação parecem ter ainda um longo caminho a percorrerconsiderando o relativo baixo número de intervenções que não individualizam a queixaescolar (25\% - 5 trabalhos).

Ainda, é importante colocar em evidência que a maioria dos trabalhos (70\% - 14 artigos) tem uma concepção ampla do fracasso escolar como um fenômeno de múltiplas faces. Portanto, é necessário salientar que a psicologia escolar/educacional já mostra avanços na área, compreendendo que ao se intervir com toda a rede de relações da escola, pode-se sim construir novas práticas de ensino-aprendizagem não particularizantes.

Assim, a psicologia deve pensar na formação de seus profissionais, que por mais que demonstrem ter um conhecimento crítico sobre a área, aparentemente não possuem ainda tantas técnicas e/ou estratégias que possam de fato não individualizar o fracasso/queixa no aluno, professor ou família. Assim sendo, é muito importante mais estudos interventivos na área, debatendo quais as possíveis ações do psicólogo diante o fracasso escolar para evitar ou minimizar os prejuízos na escolarização de modo geral.

\section{Referências}

Asbahr, F. S. F., Martins, E \& Mazzolini, B. P. M. (2011) Psicologia, formação de psicólogos e a escola: desafios contemporâneos. Psicol. estud. 16 (1), 157163.

Bray, C. T \& Leonardo, N. S. T. (2011). As queixas escolares na compreensão de educadoras de escolas públicas e privadas. Psicol. Esc. Educ., Maringá. 15 (2), 251-261.

Benedetti, M. D. et al. (2018). Medicalização e educação: análise de processos de atendimento em queixa escolar. Psicol. Esc. Educ. 22 (1), $73-81$.

Bittencourt, I. G., Lima, A. R \& Gesser, M. (2017). O trabalho em grupo como dispositivo para ressignificação da queixa escolar. Gerais, Rev. Interinst. Psicol., 10 (2), 194-203.

Botelho, L. L. R.; Cunha, C. C. A., \&Macedo, M. (2011). O método da revisão integrativa nos estudos organizacionais. Gestão e Sociedade. 5 (11), $121-136$.

Bulhoes, L. F. (2018). A construção de práticas críticas em espaços de formação do/a psicólogo/a escolar. Psicol. Esc. Educ., 22 (1), $211-213$.

Cassins, A. M. (2007). Manual de psicologia escolar - educacional. Curitiba: Gráfica e Editora. Unificado, 2007.

Elias, L. C. S \& Marturano, E. M. (2014). "Eu posso resolver problemas" e oficinas de linguagem: intervenções para queixa escolar. Psic.: Teor. e Pesq., 30 (1), 35-44.

Garcia, N. R \& Boruchovitch, E. (2014). Atribuições de causalidade para o desempenho escolar e resiliência em estudantes. Psico-USF, Itatiba. 19 (2), 277286.

Gil, A. C. (2002). Como elaborar projetos de pesquisa. (4a ed.). Atlas.

Lima, C. P., Prado, M. B. S \& Souza, B. P. (2014). Orientação quanto à queixa escolar relativa a adolescentes: especificidades. Psicol. Esc. Educ. 18 (1), 6775 .

Machado, A. M., Fernandes, A \& Rocha, M. (Org.). (2007). Novos possíveis no encontro da psicologia com a educação. Casa do Psicólogo.

MAchado, A. M \& Souza, M. P. R. (Eds.). (2004). Psicologia Escolar: Em busca de novos rumos. Casa do Psicólogo.

Negreiros, F. et al. (2017). Análise psicossocial do fracasso escolar na Educação de Jovens e Adultos. Psicol. pesq., Juiz de Fora. 11 (1), 1-2.

Oliveira, J. L. A. P., Bragagnolo, R. I \& Souza, S. P. (2014). Proposições metodológicas na intervenção com estudantes com queixa escolar. Psicol. Esc. Educ. 18 (3), 477-484.

Paiva, M. L. M. F \& Del Prette, Z. A. P. (2009). Crenças docentes e implicações para o processo de ensino-aprendizagem. Psicol. Esc. Educ. (Impr.), Campinas. 13 (1), 75- 85. 
Research, Society and Development, v. 10, n. 10, e187101018810, 2021

(CC BY 4.0) | ISSN 2525-3409 | DOI: http://dx.doi.org/10.33448/rsd-v10i10.18810

Patto, M. H. S. (1999). A Produção do Fracasso Escolar: histórias de submissão e rebeldia. Casa do Psicólogo.

Pereira, M. L .I. E. M. (2004). Projeto Prisma: Uma alternativa de trabalho com crianças com queixa escolar. Dissertação (Mestrado em Psicologia e Educação) - Universidade de São Paulo.

Pezzi, F. A. S \&Marin, A. H. (2016). "Seguindo em frente!": O fracasso escolar e as classes de aceleração. Psicol. Esc. Educ. 20 (2), $219-228$.

Pozzobon, M., Mahendra, F \& Marin, A. H. (2017). Renomeando o fracasso escolar. Psicol. Esc. Educ. 21 (3), $387-396$.

Ramos, E. T \& Stella, C. (2016). Significados da escolarização para alunos da educação de jovens e adultos. Psicol. teor. prat., 18 (2), $189-207$.

Silva, R. L. M \& Rodrigues, M. C. (2014). Atendimento à queixa escolar: experiência do projeto Seape no Centro de Psicologia Aplicada da UFJF. Psicol. rev. $20(3), 479-493$.

Souza, B. de P \& Sobral, K. R. (2007). Características da clientela da Orientação a Queixa Escolar: revelações, indicações e perguntas. In: Souza, B. de P. (Org.). Orientação à queixa escolar. Casa do Psicólogo. Cap. 5, p. 119-134.

Souza, M. P. R. (1996). A queixa escolar e a formação do psicólogo. Tese (Doutorado). Instituto de Psicologia da Universidade de São Paulo.

Zibetti, M. L. T., Souza, F. L. F \& Queiróz, K. J.M. (2010). Quando a escola recorre à psicologia: mecanismos de produção, encaminhamento e atendimento à queixa na alfabetização. Estudos e pesquisas em Psicologia. 10 (2), 490-506. 